MATEC Web of Conferences 39, 01010 (2016)

DOI: $10.1051 /$ matecconf/20163901010

(C) Owned by the authors, published by EDP Sciences, 2016

\title{
Plasma-Enhanced Atomic Layer Deposition (PEALD) of TiN using the Organic Precursor Tetrakis(ethylmethylamido)Titanium (TEMAT)
}

\author{
Z.X. Chen ${ }^{1, a}$, X. Li ${ }^{2}$, W.-M. Li ${ }^{2,3}$, and G.-Q. Lo ${ }^{1}$ \\ ${ }^{1}$ Institute of Microelectronics, A*STAR (Agency for Science, Technology and Research), 11 Science Park Road, Singapore Science Park II, \\ Singapore 117685 \\ 2 Picosun Asia Pte. Ltd., 1 North Bridge Road, \#12-01 High Street Centre, Singapore 179094 \\ ${ }^{3}$ Picosun Oy, Masalantie 365, 02430 Masala, Finland
}

\begin{abstract}
This paper presents the plasma-enhanced atomic layer deposition (PEALD) of titanium nitride (TiN) using the organic precursor tetrakis(ethylmethylamido)titanium (TEMAT), with remote ammonia $\left(\mathrm{NH}_{3}\right)$ plasma as reactant gas. This work investigates the impact of substrate temperature, from $150-350^{\circ} \mathrm{C}$, and plasma times, from 5-30s, on deposition rate, resistivity, carbon content, N/Ti ratio and film density. The lowest resistivity of $\sim 250 \mu \Omega$.cm was achieved at substrate temperatures $300-350^{\circ} \mathrm{C}$ and plasma time of $20 \mathrm{~s}$. At low substrate temperatures, although deposition was possible, carbon concentration was found to be higher, which thus affects film resistivity and density.
\end{abstract}

\section{Introduction}

Titanium nitride (TiN) has been found to be a suitable gate material to replace conventional polysilicon gate for complementary metal oxide semiconductor (CMOS) transistors [1] and has also been widely used in 3-D fieldeffect transistors (FETs) like finFETs [2] and silicon nanowire FETs [3]. This is due to its higher conductivity, high melting point, suitable work function and compatibility with high-א dielectrics. With its low resistivity, good adhesion, and process compatibility, TiN is also used as a barrier metal in the damascene process [4].

By using atomic layer deposition (ALD) [4-6], the film deposition is controlled at the atomic level, so the composition and thickness can be controlled precisely, resulting in a highly conformal deposition. Low temperature deposition is also possible with plasmaenhanced ALD (PEALD), using a remote plasma source to minimize plasma damage to the substrate or film [6]. The most commonly used precursor for ALD TiN is titanium tetrachloride $\left(\mathrm{TiCl}_{4}\right)$, together with ammonia $\left(\mathrm{NH}_{3}\right)$ [4-6]. However, growth rates are low and the hydrochloric acid $(\mathrm{HCl})$ byproduct may cause selfetching [7], copper pitting [4-5] and/or reactive site poisoning [5,7]. The drawbacks of using $\mathrm{TiCl}_{4}$ precursor has lead to research into metalorganic precursors like tetrakis(dimethylamido)titanium (TDMAT) [8-9], tetrakis(ethylmethylamido)titanium (TEMAT) [8], and tetrakis(diethylamido)titanium (TDEAT) $[8,10]$. Although TDMAT produces films at a higher deposition rate and with lower resistivity, there is higher carbon content in the film at higher temperatures from the decomposition of TDMAT [8]. TDEAT offers better precursor thermal stability and lower carbon incorporation [10], but the deposition rate is much lower and would require high substrate temperatures. TEMAT typically gives film quality and properties between those of TDMAT and TDEAT, allowing a more balanced approach to depositing TiN.

In this paper, we present a study of TiN films deposited by PEALD using the precursor TEMAT and remote ammonia $\left(\mathrm{NH}_{3}\right)$ plasma as reactant gas. Deposition was done over a large temperature range $\left(150-350^{\circ} \mathrm{C}\right)$ and using various plasma times $(5-30 \mathrm{~s})$ to determine the impact on film properties.

\section{Experiment}

Figure 1(a) shows the deposition rate and resistivity dependence on the plasma time with the substrate temperature at $250^{\circ} \mathrm{C}$. A clear drop in deposition rate and resistivity was observed as plasma time increased until saturation at 20s. This indicates a densification of the film from the formation of TiN instead of the less dense TiC or TiCN. So resistivity is also lower, since TiN is also more conductive than $\mathrm{TiC}$ or $\mathrm{TiCN}$. From the carbon concentration and N/Ti plot against plasma time in Figure $1(b)$, it is apparent that more TiN is formed at longer plasma time, given the lower carbon concentration and higher N/Ti ratio. From the density dependence on plasma time in Figure 1(c), it is clear that the TiN is denser with longer plasma time, hence the lower deposition rate. The oxygen concentration, shown in Figure 1(c), also decreases as density increases or as carbon concentration decreases. From our work on novel

\footnotetext{
a Corresponding author: chenzx@ime.a-star.edu.sg
} 

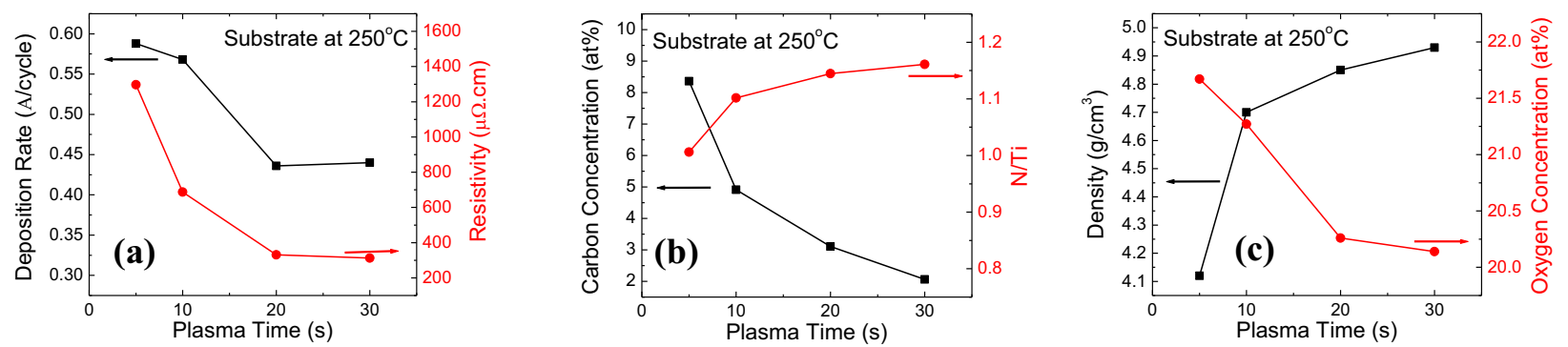

Figure 1. The (a) deposition rate and resistivity dependence, (b) carbon concentration and N/Ti ratio dependence, and (c) film density and oxygen concentration dependence on plasma time, with the substrate temperature at $250^{\circ} \mathrm{C}$.
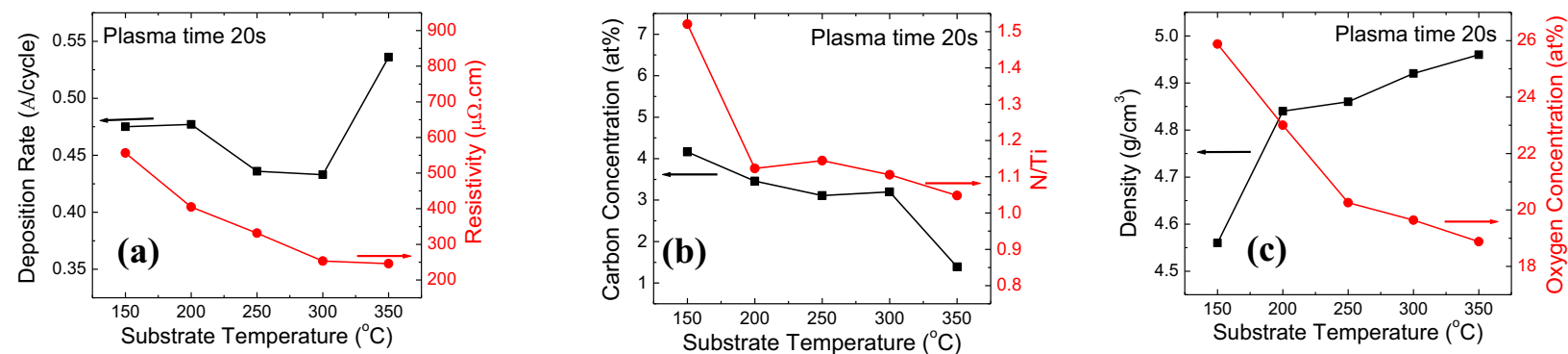

Figure 2. The (a) deposition rate and resistivity dependence, (b) carbon concentration and N/Ti ratio dependence, and (c) film density and oxygen concentration dependence on plasma time, with the plasma time at $20 \mathrm{~s}$.

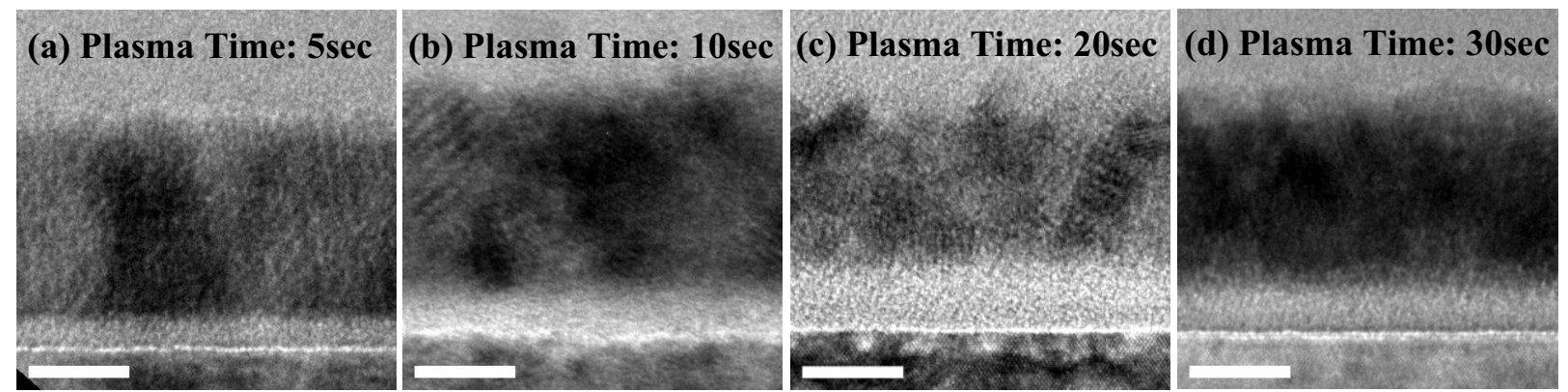

Figure 3. Transmission electron microscopy (TEM) images of PEALD TiN films processed at $250^{\circ} \mathrm{C}$ with plasma time (a) $5 \mathrm{~s}$, (b) $10 \mathrm{~s}$, (c) $20 \mathrm{~s}$, and (d) $30 \mathrm{~s}$. Scale bar is $10 \mathrm{~nm}$.
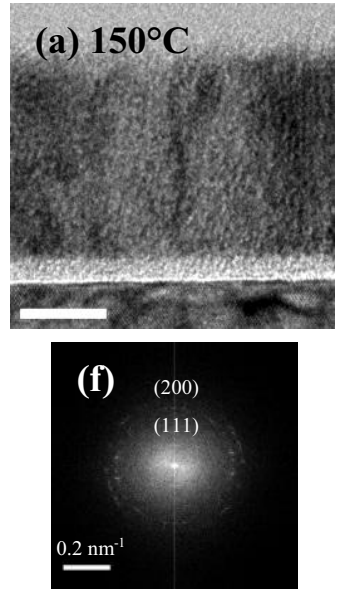
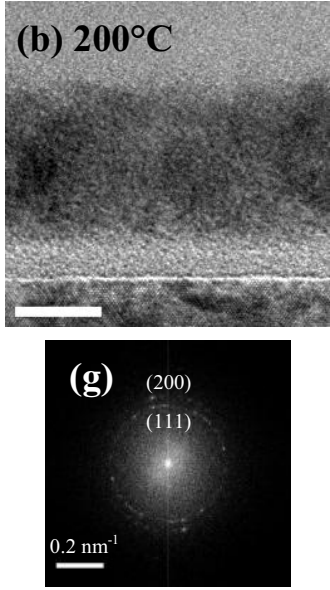
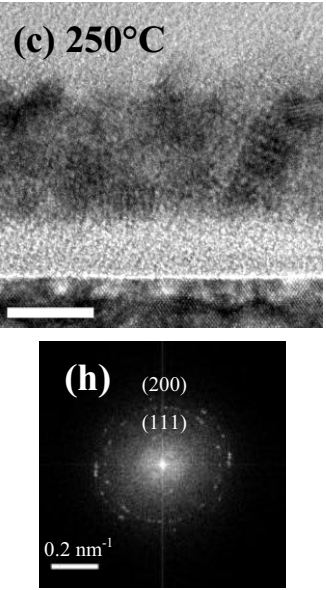
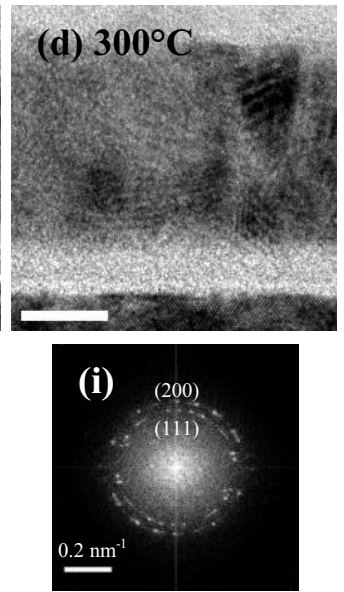
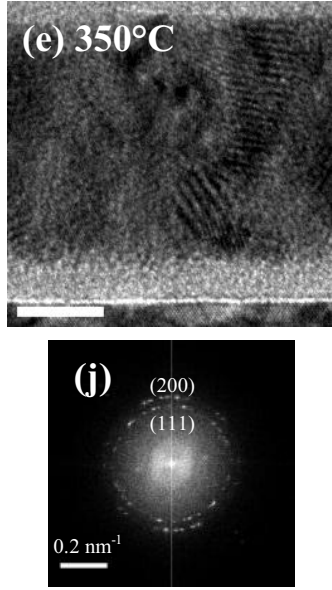

Figure 4. TEM images of PEALD TiN films processed with 20 s plasma time and substrate temperature of (a) $150^{\circ} \mathrm{C}$, (b) $200^{\circ} \mathrm{C}$, (c) $250^{\circ} \mathrm{C}$, (d) $300^{\circ} \mathrm{C}$, and (e) $350^{\circ} \mathrm{C}$, with (f)-(j) corresponding fast Fourier transform (FFT) images. Scale bar is $10 \mathrm{~nm}$, unless otherwise labelled.

ALD TiC [11], we found that TiC has higher oxygen affinity than TiN, so the more carbon concentration in the TiN film, the more it will oxidize with exposure to air.

Figure 2(a) shows the deposition rate and resistivity dependence on the substrate temperature with 20 s plasma time. The deposition rate starts to drop from $200^{\circ} \mathrm{C}$ as substrate temperature increases and then rises again at $350^{\circ} \mathrm{C}$. This indicates precursor decomposition at high temperatures. Interestingly, the resistivity is low at $350^{\circ} \mathrm{C}$, when decomposition should occur. Such deposition by precursor decomposition is similar to the work of Caubet et al. [9], where TDMAT was used, resulting in low resistivity films. The carbon concentration and N/Ti ratio, as seen in Figure $2(\mathrm{~b})$, are both high at $150^{\circ} \mathrm{C}$ possibly 


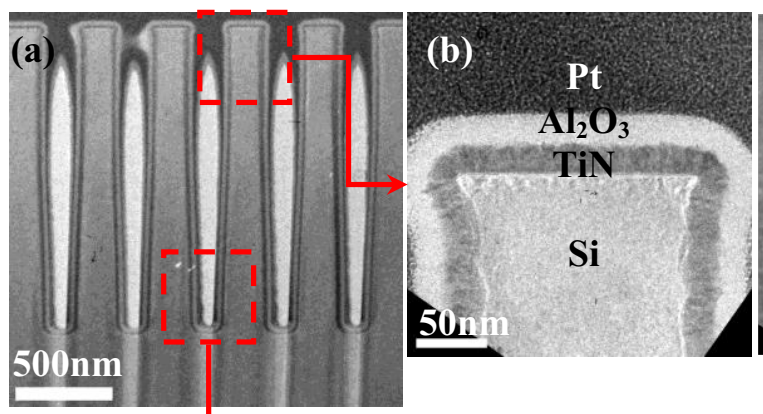

due to incomplete surface reaction of the precursor at such a low temperature. At $350^{\circ} \mathrm{C}$, both values drop, indicating most of the organic ligands were removed. Figure 2(c) shows the film density dependence on the substrate temperature, which is again dependent on the carbon concentration, since TiN has higher density than $\mathrm{TiC}$ or TiCN.

Figure 3 shows the TEM images of TiN films at different plasma times and Figure 4 shows the TEM images of films at different substrate temperatures with the inset showing the corresponding fast Fourier transform (FFT) images performed on the TiN regions. All films appear to have some crystal grains, mainly the (111) and (200) planes, as evidenced by the FFT images. The FFT images also show more defined diffraction patterns as substrate temperature increases, which indicates larger grain sizes. Figure 5(a) shows the TEM image of the PEALD TiN deposited in a deep trench structure with aspect ratio more than 6 . The TEM images of the top and bottom of the trench, Figs. 5(b) and 5(c), respectively, show excellent step coverage of the deposition, making it suitable for 3-D devices and as electrode or barrier metal.

\section{Conclusion}

The deposition of TiN by PEALD using TEMAT and plasma $\mathrm{NH}_{3}$ has been presented, along with the material properties of the films deposited under various substrate temperatures and plasma times. The fairly low resistivity of $\sim 250 \mu \Omega$.cm was achieved at substrate temperatures $300-350^{\circ} \mathrm{C}$ and plasma time of $20 \mathrm{~s}$. Low temperature deposition was found to be possible but will cause carbon concentration to increase, affecting film resistivity and density. This process is suitable for barrier metal and possibly as metal gate material, with work function tuning by varying carbon concentration.

\section{Acknowledgement}

This work was supported by Future Data Center Technologies Thematic Strategic Research Programme: NVM based on integration of PCRAM and RRAM cells with ultra scaled vertical $\mathrm{Si}$ nanowire devices (SERC Grant No: 1121720016).

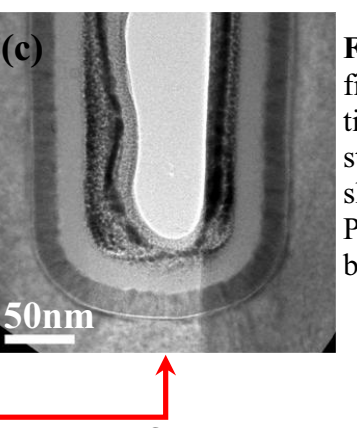

Figure 5. (a) TEM image of PEALD TiN film (substrate temperature $300^{\circ} \mathrm{C}$; plasma time 20s) deposited over a deep trench structure with aspect ratio more than 6 , showing the high conformality of the PEALD process at the (b) top and (c) bottom of the trenches.

\section{References}

1. H. Wakabayashi, Y. Saito, K. Takeuchi, T. Mogami, and T. Kunio, IEDM Tech. Dig. 1999, 253 (1999), doi: 10.1109/IEDM.1999.823891.

2. C.-Y. Kang, R. Choi, M.M. Hussain, J. Wang, J.S. Young, H.C. Floresca, M.J. Kim, J. Kim, B.-H. Lee, and R. Jammy, Appl. Phy. Lett. 91, 033511 (2007), doi: 10.1063/1.2766667.

3. K. H. Yeo, S.-D. Suk, M. Li, Y.-Y. Yeoh, K. H. Cho, K.-H. Hong, S. K. Yun, M. S. Lee, N. Cho, K. Lee, D. Hwang, B. Park, D.-W. Kim, D. Park, B.-I. Ryu, IEDM Tech. Dig. 2006, 1 (2006), doi: 10.1109/IEDM.2006.346838.

4. K.-E. Elers, V. Saanila, P. J. Soininen, W.-M. Li, J. T. Kostamo, S. Haukka, J. Juhanoja, and W. F. A. Besling, Chem. Vap. Deposition 8, 149 (2002).

5. W.-M. Li, Chem. Vap. Deposition 19, 82 (2013), doi: 10.1002/cvde.201300052.

6. K.-E. Elers, J. Winkler, K. Weeks, and S. Marcus, J. Electrochem. Soc. 152, G589 (2005), doi: 10.1149/1.1938108.

7. K.-E. Elers, T. Blomberg, M. Peussa, B. Aitchison, S. Haukka, and S. Marcus, Chem. Vap. Deposition 12, 13 (2006), doi: 10.1002/cvde.200500024.

8. G. Cho and S.W. Rhee, J. Vac. Sci. Technol. A 31, 01A117 (2013), doi: 10.1116/1.4764898.

9. P. Caubet, T. Blomberg, R. Benaboud, C. Wyon, E. Blanquet, J.-P. Gonchond, M. Juhel, P. Bouvet, M. Gros-Jean, J. Michailos, C. Richard, and B. Iteprat, J. Electrochem. Soc. 155, H625 (2008), doi: 10.1149/1.2940306.

10. J.Y. Kim, G.H. Choi, Y.D. Kim, Y. Kim, and H. Jeon, Jpn. J. Appl. Phys. 42, 4245 (2003), doi: 10.1143/JJAP.42.4245.

11. W.-M Li, X. Li, T. Pilvi, E. Østreng, C. Dezelah, Z.X. Chen, and G.-Q. Lo, ALD 2014, 99 (2014). 